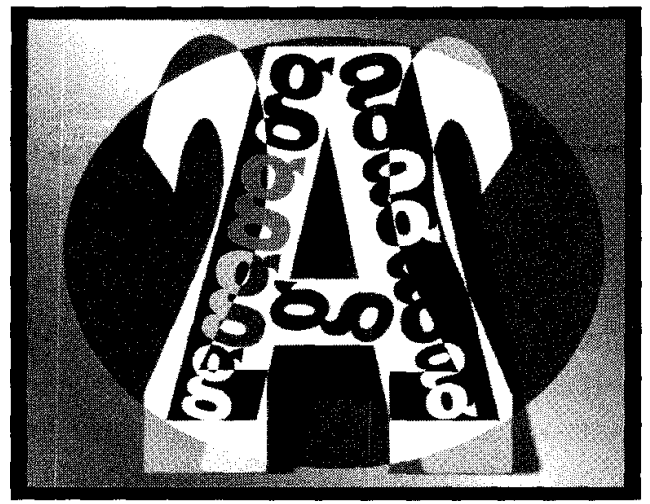

\title{
Hacia el desarrollo de una competencia binormativa ${ }^{1}$
}

Martha Jurado S.

1 igual que el resto de los hispanohablantes del dialecto mexicano, el maestro $A$ de español es susceptible de producir las secuencias que aparecen en el inciso a), aunque en una reflexión metalingüística esté consciente de que la forma prescriptivamente correcta es la que aparece en b).

(1) a. Hubieron seis detenidos

b. Hubo seis detenidos.

(2) a. Se los agradezco (a ustedes)

b. Se lo agradezco (a ustedes)

(3) a. De acuerdo a su declaración...

b. De acuerdo con su declaración...

(4) a. Háblale, ya debe haber llegado

b. Háblale, ya debe de haber llegado

Este comportamiento lingüístico disociado nos da pie para reflexionar sobre el tema del coloquio desde la perspectiva del profesor de español como segunda lengua. La presentación pretende dar respuesta a las preguntas: qué norma lingüística enseñamos, y cuál es la función del maestro de español como L2 frente al problema de la normatividad lingüística. Para responder a ellas será preciso definir una postura respecto al problema de la normatividad y esbozar algunos conceptos relativos a la metodología comunicativa y a la teoría psicolingüística sobre adquisición que la sustenta.

'Ponencia presentada en «Coloquio Cambio Lingüístico y Normatividad», celebrado en septiembre de 1999 en el Instituto de Investigaciones Filológicas. 


\section{EL PROBLEMA DE LA NORMATIVIDAD LINGÜÍSTICA}

Los lingüístas formados en las últimas décadas hemos adoptado frente a la lengua - con plena convicción - una actitud de rechazo a lo prescriptivo en favor de lo descriptivo. Así, a partir de la lingüística estructural, la norma se define en función de la observación desprovista de juicios de valor.

Esta actitud descriptiva no excluye, sin embargo, la conciencia de que las normas lingüísticas se proponen sustituir la diversidad de los usos dialectales por un sistema de carácter general que garantiza la unidad lingüística y que tiene como fin incrementar la capacidad comunicativa. Es decir, se acepta que toda lengua evoluciona y que sería inútil, e incluso contraproducente, tratar de ponerle freno; no obstante, sin ningún afán purista, también se reconoce la necesidad de intentar encauzar los cambios que se van produciendo. Dichos intentos tienen como fundamento la convicción de que en toda lengua es importante contar con una referencia normativa para los muchos casos de duda o vacilación que puedan presentarse, al menos, en lo concerniente a la lengua culta que se escribe.

En el ámbito lingüístico, el término norma puede ser interpretado, en sentido amplio, bien dentro de la división de Coseriu de «sistema, norma y habla»; bien en relación con la estandarización lingüística; bien en relación con los problemas de las normativas de las Academias, que comprenden, por ejemplo, la regulación de la ortografía. Para eludir esta posible ambigüedad manejaré los términos «norma prescriptiva» frente a «norma descriptiva».

A la norma prescriptiva pertenecen las reglas académicas para «hablar y escribir correctamente» una lengua. El léxico y la ortografía son las parcelas lingüísticas que más atención han recibido en las obras de tipo prescriptivo. En estos textos, la gramática sigue siendo la materia menos explorada, ya que los autores se limitan a censurar temas como el dequeísmo, el uso personal de haber, la posición de los clíticos, las incorrecciones en el empleo de los regímenes preposicionales, el leísmo, laísmo, y loísmo, y algunas faltas de concordancia.

Asimismo, las lenguas naturales poseen una lógica idiosincrática fundamentada tanto en las virtualidades del sistema como en los usos individuales. La aceptación social de dichos usos determina normas de comportamiento lingüístico, siempre dentro de contextos espacio-temporales, cuya delimitación es tarea del lingüísta ${ }^{2}$ - . Los cambios realizados en los usos idiomáticos se convierten en normativos cuando han sido legitimados, es decir, aceptados socialmente. El

\footnotetext{
${ }^{2}$ Para Hjemslev (1973), la norma responde a la restricción de las posibilidades del sistema y es, a la vez, una proyección global de las particularidades individuales (1973: 244). Para Coseriu (1973: 59), se presenta como restricción estadística que se articula entre el sistema y el habla.
} 
uso - los usos-, a su vez, posibilitan, fundamentan y, en ocasiones, imponen lo que suele denominarse «norma lingüística» y que nosotros manejamos como «norma lingüística descriptiva».

La normalización descriptiva condiciona, aunque con retraso, la prescripción. El condicionamiento recíproco entre prescripción y uso garantiza el necesario equilibrio dinámico que constituye la vida de las lenguas. El conocimiento de la norma permite predecir el uso; la cuantificación del uso permite conocer la norma.

El entrecruzamiento de ambos tipos de normatividad se manifiesta también en el hecho de que el lingüista descriptivo tiene que tomar decisiones respecto a qué enunciados (de entre los que ha recogido para su análisis, tanto de fuentes documentales como de su propia competencia como hablante) son aceptables y cuáles son inaceptables. Al hacer estos juicios, se entrecruzan distintos tipos de conocimiento: el que procede de su integración en una comunidad lingüística, el que ha adquirido por el hecho de pertenecer a un ámbito social y geográfico determinado y el que, necesariamente, deriva del aprendizaje de una norma prescriptiva. Al conjuntar todos estos factores se hace evidente que el lingüísta descriptivo, en cierto modo, prescribe, aunque no dicte normas.

Si aceptamos que no existe contradicción entre norma descriptiva y norma prescriptiva, asumiremos también que una clara descripción del funcionamiento de la morfosintaxis del español, con todas sus variedades y complejidades en el uso, rigurosa, pero también accesible a una gran mayoría de hablantes con conocimientos gramaticales básicos, es lo que podría ayudar a modificar la imagen tradicional del gramático como un purista anacrónico que se empeña en establecer y defender «reglas» que nadie respeta o conoce, con la autoridad inflexible que le da un lenguaje técnico e ininteligible. En efecto, la evolución continua de la lengua hace que las normas y las reglas se queden muchas veces rezagadas, con lo que el gramático prescriptivista que se aferra dogmáticamente a unos juicios que le vienen dados por sus antecesores se presenta como el modelo anticientífico, como el purista decadente al que muchos rechazan $-{ }^{3}$. Así pues, es deseable que junto a los manuales de estilo, que pretenden curar vicios, se desarrolle otro tipo de estudios más exigentes y globales que informen exactamente sobre las normas de nuestra lengua y formen a las nuevas generaciones en el conocimiento de las variedades y de sus niveles de aceptación en el amplio ámbito de la comunidad hispánica. De hecho, esta es la directriz que orienta el trabajo gramatical más ambicioso de los últimos años. Me refiero a la Gramática

\footnotetext{
${ }^{3}$ Recuérdese, por ejemplo, el artículo «Las alarmas del doctor Américo Castro», en el cual Borges (1941) pone al descubierto la parcialidad y fragilidad metodológica con la que el filólogo analiza y descalifica el idioma español hablado en Argentina.
} 
descriptiva de la lengua española (1999), una obra apadrinada por la Real Academia Española y dirigida por Ignacio Bosque y Violeta Demonte, quienes coordinaron las aportaciones de más de 73 especialistas. El título mismo de la obra es indicativo de la nueva orientación que la institución lingüística prescriptiva por antonomasia se ha visto en la necesidad de adoptar.

\section{LA NORMA Y LA ENSEÑANZA DE LA LENGUA}

Los textos de enseñanza de español con los que trabajamos en el CEPE fueron elaborados por las profesoras del Centro hace aproximadamente diez años. Surgieron como respuesta a la necesidad de contar con materiales adecuados a las características específicas de nuestra práctica: uso de la norma mexicana del español y adecuación al trabajo con grupos multilingües desde una perspectiva cultural.

La serie Pido la palabra comprende cinco textos y casetes con los que se trabajan las cuatro habilidades (comprensión auditiva, comprensión de lectura, expresión oral y expresión escrita). En los materiales auditivos se utiliza la lengua estándar en distintos registros. Para los materiales escritos se recurre a textos auténticos de distinto tipo (publicitarios, periodísticos y literarios) que utilizan la norma culta estándar del dialecto mexicano-,${ }^{4}$ ésta se convierte en el input que se produce (output) y reproduce en el aula.

La metodología comunicativa que se utiliza en los textos parte del principio de que saber una lengua involucra no sólo el conocimiento de las propiedades formales del sistema, sino también el conocimiento de cómo dicho sistema es puesto en uso en la actuación de acciones sociales de diferente tipo. Con base en este principio, el conocimiento de las reglas gramaticales que asegura la producción de oraciones bien formadas se complementa con el conocimiento de aquellas convenciones de uso que controlan su selección de acuerdo con situaciones sociales particulares. Es decir, se tiende al desarrollo de las competencias gramatical y comuncativa.

En los niveles básicos se recurre a la contextualización lingüística en situaciones significativas, con el fin de proporcionar al alumno patrones lingüísticos asociados con cierto conjunto de situaciones. En niveles avanzados se trasciende el nivel de las rutinas lingüísticas estereotipadas para desarrollar conciencia de la manera en que la lengua funciona en contextos de uso social. Se trata de que el alumno aprenda qué variedad usar en qué situación, cómo variar de estilo de acuerdo al

\footnotetext{
${ }^{4}$ Para determinar lo que entendemos por lengua estándar partimos del principio de que los usuario de la lengua aceptan alguna forma de ella como correcta; es decir, reconocen un conjunto de normas que definen lo que debe usarse. Ese conjunto de normas particular es reconocido como el más prestigioso y, por tanto, como el estándar.
} 
interlocutor, cuándo hablar y cuándo permanecer silencioso, cuándo y qué tipo de gestos acompañan a algunos enunciados, etcétera.

Distintas hipótesis sobre la adquisición de una segunda lengua dan sustento teórico al enfoque comunicativo. Una de las más desarrolladas es la del «Modelo del monitor» de Krashen (1981), quien distingue entre «adquisición» y «aprendizaje». La adquisición ocurre de manera inconsciente, como resultado de la interacción en una comunicación natural centrada en el significado. El aprendizaje aparece como resultado del estudio consciente de las propiedades formales de la lengua. El conocimiento adquirido se desarrolla gracias a un sistema innato de dominio específico y se encuentra disponible mediante un proceso automático. El conocimiento aprendido es metalingüístico por naturaleza, se almacena en el hemisferio izquierdo, pero no dentro de las áreas del lenguaje. Es procesado por los sistemas cognoscitivos generales de resolución de problemas que se desarrollan en la pubertad, durante la etapa que Piaget llama de las operaciones formales. Durante este periodo, los humanos desarrollan una habilidad general para tratar con sistemas formales abstractos. Los sistemas cognoscitivos generales de resolución de problemas se caracterizan por estar orientados a un objetivo y por utilizar la retroalimentación, la instrucción, y mecanismos como la analogía y la comprobación de hipótesis-.$^{5}$

En la actuación lingüística, el conocimiento adquirido es la fuente principal de la comprensión y producción de expresiones, mientras que el conocimiento aprendido se manifiesta a través de «el monitor», el dispositivo encargado de editarlas mediante un proceso controlado.

Como consecuencia de la adopción de la metodología comunicativa, se sigue que la norma descriptiva es adquirida y usada por los alumnos a través de la práctica de las cuatro habilidades; mientras que la norma prescriptiva es aprendida a través de reflexiones metalingüísticas, tanto de carácter gramatical (de las cuales el enfoque comunicativo no prescinde) como de las convenciones de uso que controlan la selección de acuerdo con situaciones sociales particulares. ${ }^{5}$

\footnotetext{
${ }^{5} \mathrm{La}$ diferencia entre lengua adquirida y lengua aprendida se manifiesta, por ejemplo, en el hecho de que los adultos que aprenden una segunda lengua muestran una falta de éxito general garantizado similar al que ocurre en otros campos en los cuales no existe un módulo cognoscitivo de dominio específico (por ejemplo, ajedrez, geometría o cualquier otra materia aprendida formalmente). El éxito completo en el aprendizaje de L2 es casi inexistente, ya que siempre persisten acentos y falta de intuición sobre juicios gramaticales sutiles. También hay variación en las estrategias de aprendizaje y en los objetivos (por ejemplo, algunos adultos desarrollan sistemas "pidginizados", otros cubren solamente ciertas necesidades comunicativas específicas; oros alcanzan cierto estado y se "fosilizan", etc.). Finalmente, en el aprendizaje de L2 juegan un papel importante la instrucción formal y los valores afectivos.
} 
Así el tratamiento de los temas gramaticales da pie a que, en los niveles intermedios y avanzados, se introduzcan también algunas observaciones de carácter prescriptivo. Por ejemplo, al explicar el funcionamiento gramatical de la pasiva refleja y del se impersonal, se comenta que pueden escucharse en la lengua hablada secuencias como «se vende periódico», aunque es preferible usar la construcción concordada. En otros casos se recurre al análisis de errores. Se presentan secuencias correctas e incorrectas que el alumno tiene que identificar como tales. En ellas se mezclan errores producto del interlenguaje de los alumnos [(5)a, (6)a, (7)a] con usos prescriptivamente incorrectos producidos por nativohablantes $[(5) b ;(6) b, c ; 7 b]$. Se tratan así problemas relacionados con el gerundio (5); con las preposiciones y frases prepositivas (6), y con la concordancia (7).

(5) a. ....pero dejando de ayudar a los países pobres no es la mejor solución b. la carta conteniendo la orden de presentación

(6) a. los sacerdotes vestían en negro

b. en base a su respuesta

c. en relación a...

(7) a. la principal problema

b. un grupo de personas salieron

Los problemas relativos al léxico generalmente se mencionan en notas a pie de página; por ejemplo, se recomienda el uso de influir o de competencia sobre influenciar o competición - respectivamente-, y se explica por qué una forma es más conveniente que otra, aunque se aclara que en el uso se pueden escuchar ambas variantes.

Como puede apreciarse, al trabajar la norma prescriptiva en relación con la gramática, el maestro presenta las formas que compiten entre sí (por proceder de variedades, de géneros o de estilos diferentes), haciendo a un lado el anatema que condena usos por sí mismos. Lo recomendable es explicar por qué existen y por qué se estigmatizan estas expresiones, para que el alumno pueda decidir sobre ellas. Esta sería, desde mi perspectiva, la función del maestro de español como L2: desarrollar en el alumno extranjero una competencia binormativa, es decir, la capacidad de entender y comunicarse utilizando la norma descriptiva, aunada a la capacidad de reflexionar metalingüísticamente sobre los usos pertenecientes a la norma prescriptiva.

La experiencia nos ha mostrado que, en muchos casos - sobre todo tratándose de alumnos europeos-, el desarrollo de esta competencia binormativa (que podría 
parecer a simple vista un objetivo difícil de alcanzar) es el resultado natural de nuestro trabajo. Ello se debe, por una parte, a la conjunción metodológica de adquisición y aprendizaje, de uso y gramática; por otra, a las operaciones de contraste y analogía que el alumno, a través de sus sistemas cognoscitivos generales de resolución de problemas, establecen inevitablemente entre sus conocimientos lingüísticos previos y el nuevo código que va construyendo. Es decir, además del conjunto de oraciones bien formadas de - al menos- su lengua materna, el estudiante de español posee una gran cantidad de información acerca del carácter general de una lengua (por ejemplo, la existencia, diferencias fonológicas, estilísticas, de registro y dialectales, así como de elementos deícticos, anáforicos, etc.) Toda esta información previa interactúa en la construcción del nuevo código dando como resultado un buen cúmulo de conocimiento metalingüístico que facilita la formación de una competencia de carácter binormativo. Así algunos alumnos logran desarrollarla en tal grado que, incluso, «corrigen» a sus amigos mexicanos.

Esta posición frente a la normatividad representa, asimismo, la conciliación de una metodología que adopta el rendimiento comunicativo como criterio básico para definir la norma con la que se trabaja, con la concepción de que la finalidad de la norma es disponer de una lengua común que sirva para cumplir los requisitos de comunicación entre hablantes de diferentes variedades.

En conclusión, en esta época caracterizada por la preeminencia de la lengua oral, la introducción masiva de términos procedentes de otras lenguas, la mezcla de niveles, el ejercicio de innovación continua que realiza la publicidad, la desaparición de los tabúes, el reclamo de tratamiento justo por parte de grupos tradicionalmente desfavorecidos y el cuestionamiento de toda imagen de autoridad restrictiva, la función de cualquier maestro de español (y no exclusivamente del maestro de español como L2) es desarrollar en los alumnos una conciencia metalingüística que les permita ser bicompetentes, adecuar su actuación lingüística eligiendo conscientemente la norma apropiada a los distintos contextos, ya que - como dice Gómez Torrego- “... la norma debe conocerse siempre, aunque a veces sea para conculcarla o transgredirla por razones estilísticas o expresivas. Lo imperdonable es la ignorancia" (Gómez Torrego, 1995: 10).

BIBLIOGRAFÍA

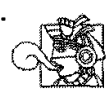

Álvarez Martínez, Ma. Ángeles. "Las gramáticas y las normas", en Revista Española de Lingüística. Vol. 19, núm. 2, 1989, pp. 435-444.

Borges, Jorge L. (1941) "Las alarmas del doctor Américo Castro", en La peculiaridad lingüística rioplatense y su sentido histórico. Buenos Aires, Losada. 
Bosque, I. y Violeta Demonte. Gramática descriptiva de la lengua española. Madrid, Espasa, 1999.

Catalá Torres, Natalia. "Prescripción, norma e intuición", en Revista Española de Lingüística. Vol. 19, núm. 1, 1989, pp. 63-70.

Coseriu, Eugenio (1973) “Sistema, norma y habla”, en Teoría del lenguaje y lingüística general. Madrid, Gredos.

GarRido Medina, Joaquín. "Norma interna y externa en español y gramática comunicativa: el ejemplo del gerundio", en Actas del segundo congreso nacional del ASELE. Madrid, 1990. Salvador Montesa Peydró y Antonio Garrido Moraga (comp.). Málaga, 1994.

Gómez Torrego, Leonardo (1995) El léxico en el español actual: uso y norma. Madrid, Arco/Libro.

(1993) Manual de español correcto. Tomos I y II. Madrid, Arco/Libro. Huelmslev, L (1976) Principios de gramática general. Madrid, Gredos. [1a. ed. 1928] KRASHEN, S.D. (1981) Second Language Acquisition and Second Language Learning. Oxford, Pergamon Press.

Widdowson, H.G. y C. CRIPER. (1975) "Sociolinguistics and Language Teaching" en The Edinburgh Course in Applied Linguistics: Papers in Applied Linguistics. J. P. Allen y P. Corder (eds.) Vol. II, Oxford, OUP, pp. 155-217. 